Please do not remove this page

RMIT

UNIVERSITY

\title{
Predicting the sound insulation of lightweight sandwich panels
}

Davy, John; Cowan, Andre; Pearse, John; Latimer, Michael

https://researchrepository.rmit.edu.au/esploro/outputs/9921859529101341/filesAndLinks?institution=61RMIT_INST\&index=null

Davy, J., Cowan, A., Pearse, J., \& Latimer, M. (2013). Predicting the sound insulation of lightweight sandwich panels. Building Acoustics, 20(3), 177-192. https://doi.org/10.1260/1351-010X.20.3.177

Document Version: Published Version

Published Version: https://doi.org/10.1260/1351-010X.20.3.177

Repository homepage: https://researchrepository.rmit.edu.au

(c) 2014 Multi-Science Publishing

Downloaded On 2023/04/26 20:44:32 +1000

Please do not remove this page 
Thank you for downloading this document from the RMIT Research Repository.

The RMIT Research Repository is an open access database showcasing the research outputs of RMIT University researchers.

RMIT Research Repository: http://researchbank.rmit.edu.au/

\section{Citation:}

Davy, J, Cowan, A, Pearse, J and Latimer, M 2013, 'Predicting the sound insulation of lightweight sandwich panels', Building Acoustics, vol. 20, no. 3, pp. 177-192.

See this record in the RMIT Research Repository at:

https://researchbank.rmit.edu.au/view/rmit:26078

Version: Accepted Manuscript

Copyright Statement: (c) 2014 Multi-Science Publishing

Link to Published Version:

http://dx.doi.org/10.1260/1351-010X.20.3.177 


\title{
Predicting the Sound Insulation of Lightweight Sandwich Panels
}

\author{
John L. Davy ${ }^{1,2}$, Andre Cowan ${ }^{3}$, John R. Pearse ${ }^{3}$, Michael Latimer ${ }^{4}$ \\ ${ }^{1}$ School of Applied Sciences, Royal Melbourne Institute of Technology (RMIT) \\ University, GPO Box 2476V Melbourne, Victoria 3001, Australia, \\ john.davy@rmit.edu.au \\ ${ }^{2}$ CSIRO Materials Science and Engineering, PO Box 56 Highett Victoria 3190, \\ Australia,john.davy@csiro.au \\ ${ }^{3}$ University of Canterbury, Mechanical Engineering, Private Bag 4800, Christchurch \\ 8140,New Zealand,andre.cowan@marshallday.co.nz, john.pearse@canterbury.ac.nz \\ ${ }^{4}$ Pyrotek, 69 Cryers Road, Manukau, Auckland 2013, New Zealand, \\ miclat@pyrotek-inc.com
}

(Received 17 August 2013 and accepted 9 January 2014)

\begin{abstract}
The sound insulation of three sandwich panels was modelled using simple sound insulation prediction methods, but the agreement between theory and experiment was not very good. The effective Young's modulus was determined over a wide frequency from the resonant frequencies of three beams of different lengths. The effective Young's modulus was found to reduce with increasing frequency as has been predicted in the literature. This decrease is due to the core starting to shear rather than bend because its Young's modulus is much less than the Young's moduli of the skins. Unfortunately the agreement between theory and experiment was still not very good. This is because many of the prediction frequencies occur in the critical frequency dip because of the variation of the Young's modulus with frequency.
\end{abstract}

\section{INTRODUCTION}

Light weight sandwich panels are often used in the construction of marine craft because of their light weight but high strength and stiffness. The sound insulation of three such panels was measured at the University of Canterbury using the sound intensity technique ${ }^{1}$. It was calculated that the mass-stiffness-mass resonance frequency of these three sandwich panels would be above $10 \mathrm{kHz}$ and could be ignored. Thus the three sandwich panels were modelled as homogeneous isotropic panels. The effective masses per unit area, the effective Young's moduli and the effective damping loss factors for the homogeneous isotropic models were determined by measurements on sample beams of the materials ${ }^{2}$. The homogenised models were used to predict the sound insulation of the panels using the single leaf theory of Davy ${ }^{3}$. Brunskog ${ }^{4}$ has removed some of the 
assumptions made by Davy and used a slightly different method of combining the theories that apply above and below the critical frequency. However his theoretical results are fairly similar to those of Davy.

The agreement between the predicted and the measured sound insulation of the panels was not as good as had been expected. The effective Young's moduli and the effective damping loss factors had only been measured with one beam length. These initial measurements suggested that, as had been expected, the effective Young's moduli and the effective damping loss factors were constant with frequency and this was assumed in the theoretical predictions of the sound insulation. Because usually only the first five beam modes can be used, the range of frequencies at which the measurements of the effective Young's moduli and the effective damping loss factors were made was considerably less than the range over which the sound insulation measurements and predictions had been made. Thus it was suggested that the effective Young's moduli and the effective damping loss factors might vary with frequency.

\section{YOUNG'S MODULUS AND DAMPING LOSS FACTOR}

\subsection{Measurements on Beams}

To obtain measurements of the effective Young's moduli and the effective damping loss factors over a wider frequency range, beams of one half and one quarter of the length of the original beams were used. These measurements showed that the effective Young's moduli were constant at low frequencies, but decreased with increasing frequency at the higher frequencies. The effective damping loss factors were constant with frequency. The beam measurements were made with the beams clamped (fixed) at one end and free at the other end, and with the beams free at both ends. These two beam mounting methods produced slightly different results. This is due to the clamped end inducing shear in the beam ${ }^{5}$ and the loss of bending wave energy at the clamping device.

According to Cremer et al..$^{6}$, the wave number $k_{n}$ of the $n$th mode of a beam of length $L$ is given by

$$
k_{n}=\frac{x_{n}}{L} .
$$

For a beam which is clamped (fixed) at one end and free at the other end, $x_{n}$ is the solution of the equation

$$
\cosh \left(x_{n}\right) \cos \left(x_{n}\right)+1=0
$$

For a beam which is free at both ends, $x_{n}$ is the solution of the equation

$$
\cosh \left(x_{n}\right) \cos \left(x_{n}\right)-1=0 .
$$

The first five solutions of equations (2) and (3) are given in Table 1.

From the equations in Cremer et al. ${ }^{6}$, the effective Young's modulus $E$ of the isotropic homogeneous model of the beam can be shown to be given by 
Table 1 First five modal factors for fixed-free and free-free beams

\begin{tabular}{lll}
\hline $\mathbf{n}$ & fixed-free & free-free \\
\hline 1 & 1.8751 & 4.7300 \\
2 & 4.6940 & 7.8532 \\
3 & 7.8547 & 10.9956 \\
4 & 10.9955 & 14.1372 \\
5 & 14.1372 & 17.2788 \\
& & \\
& $E=12 \rho\left(\frac{2 \pi f_{n}}{k_{n}^{2} t}\right)^{2}=\frac{48 \pi^{2} \rho L^{4} f_{n}^{2}}{x_{n}^{4} t^{2}}$,
\end{tabular}

and the effective damping loss factor $\eta$ can be shown to be given by

$$
\eta=\frac{\Delta f_{n}}{f_{n}} .
$$

In these equations, $\rho$ is the density of the isotropic homogeneous model of the beam, $t$ is the thickness of the beam in the direction of the vibration of the beam, $f_{n}$ is the resonant frequency of the $n$th mode of the beam and $\Delta f_{n}$ is the half power or $3 \mathrm{~dB}$ bandwidth of the $n$th mode of the beam.

The measurements were made in general accordance with the method described in $\mathrm{ASTM}^{2}$. The beam was excited on its centre line with a PCB Electronics T086C01 impact hammer and its response was measured with a Brüel and Kjær 4519 accelerometer. Each measurement was repeated three times. A Fast Fourier transform was performed on the response to convert it to a relative frequency response over the frequency range of interest. The modal frequencies and modal half power bandwidths were measured for up to the first five modes and the effective Young's modulus and the effective damping loss factor were calculated using the equations given above. To obtain a larger frequency range three different lengths of beam were used. For the fixedfree case, the unclamped beam lengths were 470, 235 and $118 \mathrm{~mm}$. For the free-free case the beam lengths were 602,363 and $235 \mathrm{~mm}$. Free-free measurements made on the skin and core of one of the sandwich beams used lengths of 602, 300 and $149 \mathrm{~mm}$ and 501, 297 and $150 \mathrm{~mm}$. For two of the sandwich panels, Anders ${ }^{7}$ used $947.5 \mathrm{~mm}$ for his free-free measurements and $800 \mathrm{~mm}$ for his fixed-free measurements. All the beams used were about $50 \mathrm{~mm}$ wide.

\subsection{Calculation from Measured Sound Insulation}

The effective Young's modulus was also back calculated by determining the value which made the single leaf theory of Davy ${ }^{3}$ agree with the measured sound insulation of the sandwich panels. Because the calculated values were often in the critical frequency dip, two values of Young's modulus were usually possible. Generally the lowest value of Young's modulus was chosen. The aim was to produce a graph which 
was as close as possible to a straight line on a log-log graph of Young's modulus versus frequency. There was rough agreement between the back calculated values and the fixed-free and free-free values of the Young's moduli, except at the low frequencies where the back calculated values continued to increase with decreasing frequency while the beam measurement values became constant with frequency. Because the influence of the effective Young's modulus on the predicted sound insulation becomes very small as the frequency is decreased, there was a lower frequency, which varied between sandwich panels and measurements, below which it was not possible to apply this technique or below which it produced nonsensical values. For the same reason the uncertainty of the Young's modulus determined by the back calculation method becomes much greater at low frequencies, even when a seemingly sensible value can be obtained. This is also believed to be the reason why at low frequencies the back calculated values continued to increase with decreasing frequency while the beam measurement values became constant with frequency.

\subsection{Kurtze and Watters' Theory}

A quick literature search revealed that Young's moduli for sandwich panels and beams which vary with frequency had been predicted by Kurtze and Watters ${ }^{8}$. The Young's moduli of the skins and the core of one of the sandwich panels were determined by beam measurements. These measured Young's moduli were used to calculate the effective Young's modulus of the sandwich panel as a function of frequency using the theory of Kurtze and Watters ${ }^{8}$. The calculated values agreed reasonably well with the values measured with the fixed-free and free-free experiments on the sandwich beams and with the back calculated values at the higher frequencies.

According to equation (12b) of Kurtze and Watters ${ }^{8}$, the transverse wave speed $c$ of a symmetrical sandwich panel below the mass-stiffness-mass resonance is given by the following cubic equation in $c^{2}$

$$
\left(\frac{c_{s}}{c_{b}}\right)^{4} c^{6}+c_{s}^{2} c^{4}-c_{s}^{4} c^{2}-c_{b}^{\prime 4} c_{s}^{2}=0 .
$$

$c_{b}$ is the bending wave speed of the sandwich panel which is given by

$$
c_{b}^{4}=\frac{B_{t}}{M_{t}} \omega^{2},
$$

where $\omega$ is the angular frequency.

$c^{\prime}{ }_{b}$ is the bending wave speed of a single skin panel loaded with half the mass of the core panel which is given by

$$
c_{b}^{\prime 4}=\frac{2 B_{1}}{M_{t}} \omega^{2} .
$$


$c_{s}$ is the shear wave speed of the core layer loaded with the mass of the skin panels which is given by

$$
c_{s}^{2}=\frac{G_{2}}{\rho_{t}} .
$$

$M_{t}$ and $\rho_{t}$ are the total mass per unit area and the average density of the sandwich panel which are related by

$$
M_{t}=\rho_{t} t=\rho_{t}(2 a+b) .
$$

$B_{t}$ is the effective bending stiffness of the sandwich panel which is given by

$$
B_{t}=\frac{2 E_{1}}{3\left(1-\mu_{1}^{2}\right)}\left[\left(\frac{b}{2}+a\right)^{3}-\left(\frac{b}{2}\right)^{3}\right]+\frac{E_{2} b^{3}}{12\left(1-\mu_{2}^{2}\right)},
$$

where $E_{1}, \mu_{1}$ and $a$ are the effective Young's Modulus, the effective Poisson's ratio and thickness of one of the skin panels. $E_{2}, \mu_{2}$ and $b$ are the Young's Modulus, the Poisson's ratio and the thickness of the core panel.

$B_{1}$ is the bending stiffness of one of the skin panels which is given by

$$
B_{1}=\frac{E_{1} a^{3}}{12\left(1-\mu_{1}^{2}\right)}
$$

and $G_{2}$ is the shear modulus of the core which is given by

$$
G_{2}=\frac{E_{2}}{2\left(1+\mu_{2}\right)} \text {. }
$$

The effective Young's Modulus $E$ of the sandwich panel given by

$$
E=12 \rho_{t}\left(1-\mu^{2}\right)\left[\frac{c^{2}}{(b+2 a) \omega}\right]^{2}
$$

where $\mu$ is the effective Poisson's ratio of the sandwich beam. The skins on each side of the $23 \mathrm{~mm}$ sandwich panel were slightly different from each other, but that was ignored in this analysis. All the Poisson's ratios were assumed to be 0.3 .

Since Kurtze and Watters ${ }^{9}$ pioneering theoretical and experimental research on the acoustics of sandwich panels, there have been a significant number of papers published in the area. Some typical examples are Ford et al. ${ }^{9}$, Dym and Lang ${ }^{10}$, Dym et al. ${ }^{11}$, 
Jones $^{12}$, Makris et al. ${ }^{13}$, Nilsson ${ }^{14}$, Moore and Lyon ${ }^{15}$, Lauriks et al. ${ }^{16}$, Bolton et al. ${ }^{17}$, Nilsson and Nilsson ${ }^{5}$, Wang et al. ${ }^{18}$ and Sargianis and Suhr ${ }^{19}$. Many of these papers extend Kurtze and Watters ${ }^{8}$ research to include the frequency range in the region of and above the mass-stiffness-mass resonant frequency which Kurtze and Watters ${ }^{8}$ did not consider. Kurtze and Watters' ${ }^{8}$ simple approach still appears to be reasonably accurate below the mass-stiffness-mass resonant frequency of the sandwich panel and that frequency range was the only one that needed to be considered for the sandwich panels investigated in this paper. It should be noted that Rinde ${ }^{20}$ used Kurtze and Watters' 8 theory to calculate the effective bending wave phase speed of a thick homogeneous isotropic panel. The aim of this paper was to combine Kurtze and Watters' ${ }^{8}$ calculated values of the effective Young's modulus or the measured effective Young's modulus with a simple sound insulation prediction method ${ }^{3}$ in the frequency range below the mass-stiffness-mass resonant frequency. If the mass-stiffness-mass resonant frequencies had been lower, it would have been necessary to adopt the more complicated methods of the more recent papers.

\subsection{Comparison of Results}

Three sandwich panels were measured in this study. They had thicknesses of 23, 14 and $42 \mathrm{~mm}$ respectively and average densities of 374,243 and $86 \mathrm{~kg} / \mathrm{m}^{3}$. The $23 \mathrm{~mm}$ thick sandwich panel had an $18.9 \mathrm{~mm}$ thick rigid PVC foam core of density $120 \mathrm{~kg} / \mathrm{m}^{3}$. One outer skin was $2.1 \mathrm{~mm}$ thick and consisted of 3 layers of E-Glass Quadraxial cloth with a surface density per layer of $0.6 \mathrm{~kg} / \mathrm{m}^{2}$ impregnated with resin. The other outer skin was $1.8 \mathrm{~mm}$ thick consisted of 2 layers of E-Glass Quadraxial cloth with a surface density per layer of $0.6 \mathrm{~kg} / \mathrm{m}^{2}$ impregnated with resin. The $14 \mathrm{~mm}$ thick sandwich panel had a $12 \mathrm{~mm}$ thick rigid PVC foam core of density $60 \mathrm{~kg} / \mathrm{m}^{3}$. Each of its outer skins was $1 \mathrm{~mm}$ thick with a surface density $0.41 \mathrm{~kg} / \mathrm{m}^{2}$ and consisted of double bias E-Glass cloth and $30 \%$ of resin. The $42 \mathrm{~mm}$ thick sandwich panel had a $40 \mathrm{~mm}$ thick rigid PVC foam core of density $45 \mathrm{~kg} / \mathrm{m}^{3}$. Each of its outer skins was $1 \mathrm{~mm}$ thick with a surface density $0.265 \mathrm{~kg} / \mathrm{m}^{2}$ and consisted of double bias E-Glass cloth and $30 \%$ of resin.

The Young's modulus of the $23 \mathrm{~mm}$ thick panel is shown in Figure 1. The two measured values and the calculated value are approximately equal and approximately constant as a function of frequency below $1 \mathrm{kHz}$. In this frequency range, these values show why it was easy to conclude that the effective Young's modulus was constant. Above $1 \mathrm{kHz}$, all four values are approximately equal and decrease as the frequency increases. The other values are in qualitative agreement with Kurtze and Watters's theory. Below $1 \mathrm{kHz}$, the back calculated value increases as the frequency decreases and becomes significantly different from the other three values. This is believed to be due to the sound insulation theory under estimating the measured sound insulation in this frequency range. This under estimation is offset by making the back calculated value larger than it actually should be. The fixed-free values were always lower than the freefree values, and with one exception the calculated values were always lower than the fixed-free values.

The calculated and back calculated values were calculated at third octave band centre frequencies. The measured values were only known at the resonant frequencies of the beams used for measurement. To enable the use of these values for predicting the 


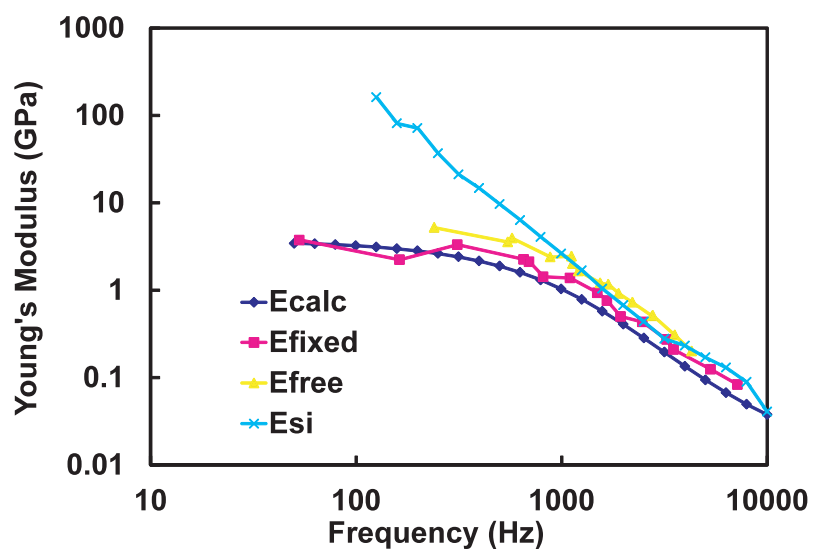

Figure 1. The effective Young's modulus of a $23 \mathrm{~mm}$ thick sandwich panel. Efixed is measured using beams with one end fixed and the other end free. Efree is measured using beams with both ends free. Ecalc is calculated from the measured Young's moduli of the two skins and the core. Esi is back calculated from the measured sound insulation of the panel.

sound insulation at third octave band centre frequencies, the average value was calculated below a dividing frequency, and at and above that frequency a straight line was best fitted to the measured values in the log modulus log frequency domain. For the fixed-free measurements, the dividing frequency was $655 \mathrm{~Hz}$. The equation derived was

$$
E=\min \left(3.14,19415 f^{-1.387}\right) \mathrm{GPa},
$$

where $f$ is the frequency in Hz. The $R^{2}$ value for sloping section of the line was 0.9862 . For the free-free measurements, the dividing frequency was $884 \mathrm{~Hz}$. The equation derived was

$$
E=\min \left(4.32,163332 f^{-1.608}\right) \mathrm{GPa}
$$

The $R^{2}$ value for the sloping section of the line was 0.9801 .

The damping loss factor of the $23 \mathrm{~mm}$ thick sandwich panel is shown in Figure 2. Above $1 \mathrm{kHz}$, the fixed-free and free-free values show reasonable agreement. Below 1 $\mathrm{kHz}$, the fixed-free values are larger than the free-free values. This is believed to be due losses at the clamped (fixed) end. The values are relatively constant as a function of frequency. Thus the average values were calculated. The average values were 0.029 for the fixed-free beam and 0.021 for the free-free beam. The fixed-free average value was used when back calculating the Young's modulus from the sound insulation measurements. 


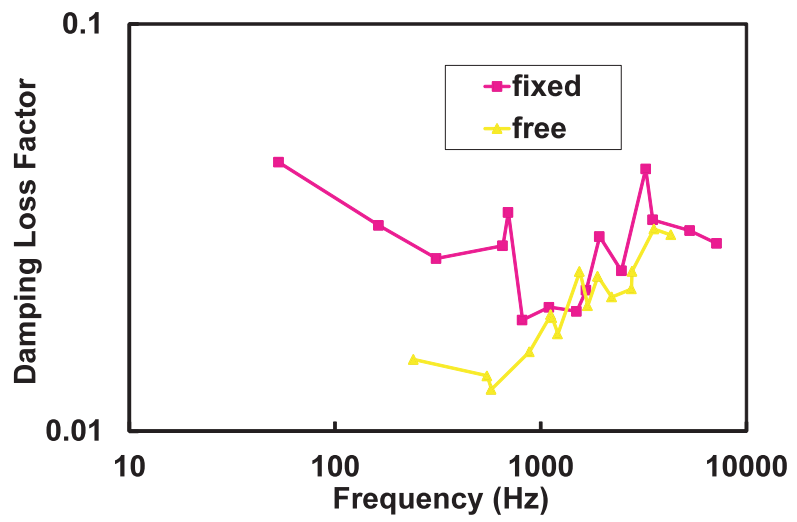

Figure 2. The effective damping loss factor of a $23 \mathrm{~mm}$ thick sandwich panel. fixed is measured using beams with one end fixed and the other end free. free is measured using beams with both ends free.

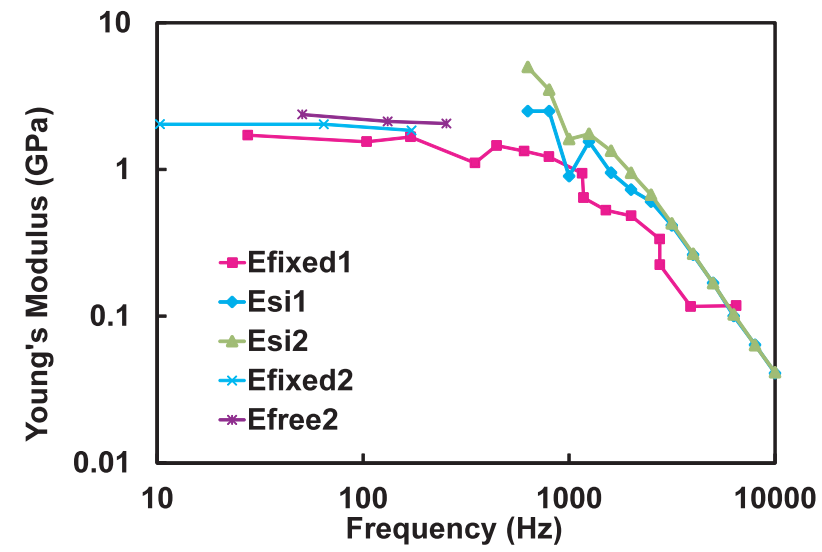

Figure 3. The effective Young's modulus of a $14 \mathrm{~mm}$ thick sandwich panel. Efixed1 and Efixed2 are measured using beams with one end fixed and the other end free. Efree 2 is measured using beams with both ends free. Esi1 and Esi2 are back calculated from the measured sound insulation of the panel.

The Young's modulus of the $14 \mathrm{~mm}$ thick panel is shown in Figure 3. The values suffixed with 1 were calculated from measurements made by the second author. The values suffixed with 2 were calculated from measurements made by Anders ${ }^{7}$. The values are approximately constant as a function of frequency below $1 \mathrm{kHz}$ and decrease with increasing frequency above $1 \mathrm{kHz}$. The free-free values are greater than the fixedfree values. For the fixed-free measurements, the dividing frequency was $798 \mathrm{~Hz}$. The equation derived was 


$$
E=\min \left(1.44,4674.5 f^{-1.233}\right) \mathrm{GPa} .
$$

The $R^{2}$ value for sloping section of the line was 0.9261 .

The damping loss factors for the 14 and $42 \mathrm{~mm}$ sandwich panels are shown in Figure 4. They are relatively constant with frequency and thus an average across frequency was taken. The average values were 0.054 and 0.041 for the 14 and $42 \mathrm{~mm}$ thick panels respectively.

Figure 5 shows the effective Young's modulus of the $42 \mathrm{~mm}$ sandwich panel. The measured values are relatively constant below $600 \mathrm{~Hz}$. Above $600 \mathrm{~Hz}$, all the values

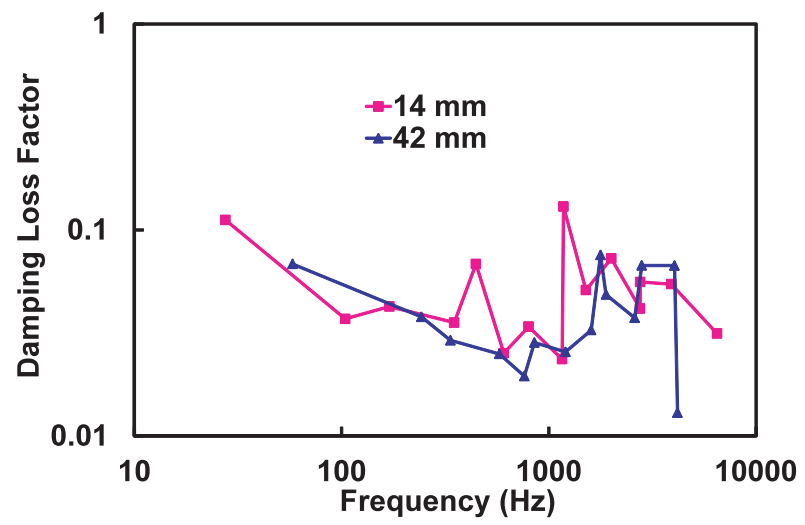

Figure 4. The effective damping loss factors of $14 \mathrm{~mm}$ and $42 \mathrm{~mm}$ thick sandwich panels measured using beams with one end fixed and the other end free.

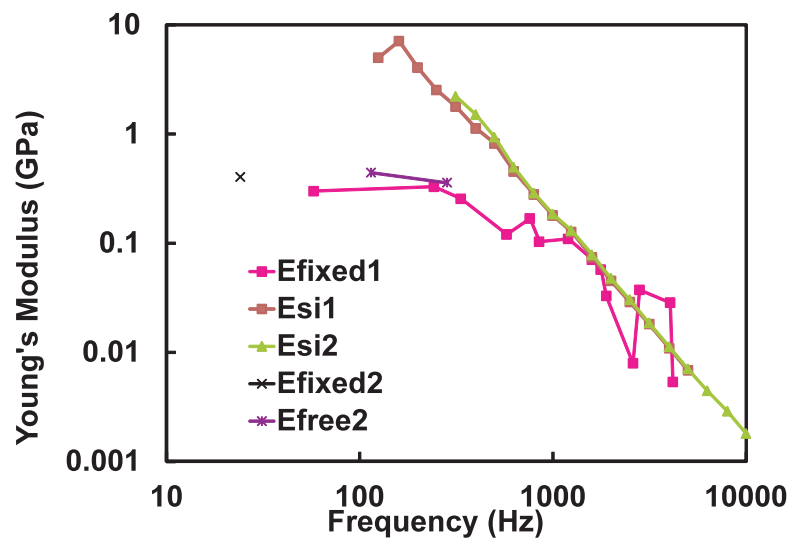

Figure 5. The effective Young's modulus of a $42 \mathrm{~mm}$ thick sandwich panel. Efixed1 and Efixed2 are measured using beams with one end fixed and the other end free. Efree2 is measured using beams with both ends free. Esi1 and Esi2 are back calculated from the measured sound insulation of the panel. 
decrease with increasing frequency and are approximately equal. Below $600 \mathrm{~Hz}$, the back calculated values continue to increase with decreasing frequency and are different from the measured values. Again, this is believed to be due to under estimation by the sound insulation theory. The two free-free measured values are greater than the fixedfree values for similar frequencies. For the fixed-free measurements, the dividing frequency was $577 \mathrm{~Hz}$. The equation derived was

$$
E=\min \left(0.294,1523 f^{-1.406}\right) \mathrm{GPa} .
$$

The $R^{2}$ value for sloping section of the line was 0.7045 . The exponents in equations (15) to (18) are, in order of increasing magnitude, $-1.233,-1.387,-1.406$ and -1.608 , giving an average value of -1.409 and a standard deviation of 0.154 . Thus these exponents are all fairly similar.

A beam cut from the $23 \mathrm{~mm}$ sandwich panel was delaminated into its skins and core. Measurements were made with the free-free beam configuration. The measured Young's moduli of the skin and core of the $23 \mathrm{~mm}$ thick laminate are shown in Figure 6. In contrast to the three sandwich beams, the skin and core have Young's moduli which are nearly constant with frequency. This shows that the variable Young's moduli of the sandwich beams were not due to the measurement technique. The Young's moduli of the skin and core were 6.89 and $0.0967 \mathrm{GPa}$ respectively. Figure 7 shows the damping loss factor of the skin and core of the $23 \mathrm{~mm}$ sandwich beam. Again these are relatively constant with frequency. The averages over frequency are 0.031 and 0.047 for the skin and core respectively. It is interesting that these are both higher than the 0.029 and 0.021 measured for the sandwich panel with the fixed-free and free-free beams respectively.

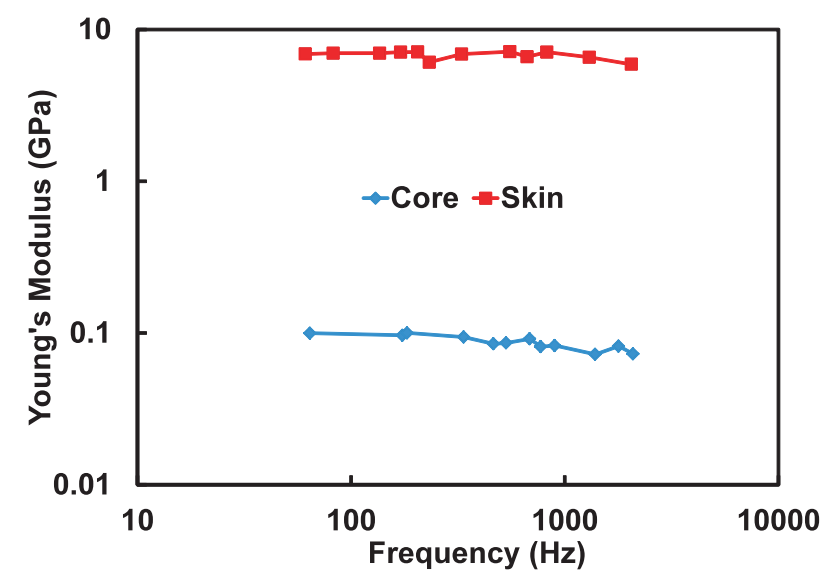

Figure 6. The Young's moduli of the core and the skins of a $23 \mathrm{~mm}$ thick sandwich panel measured using beams with both ends free. 


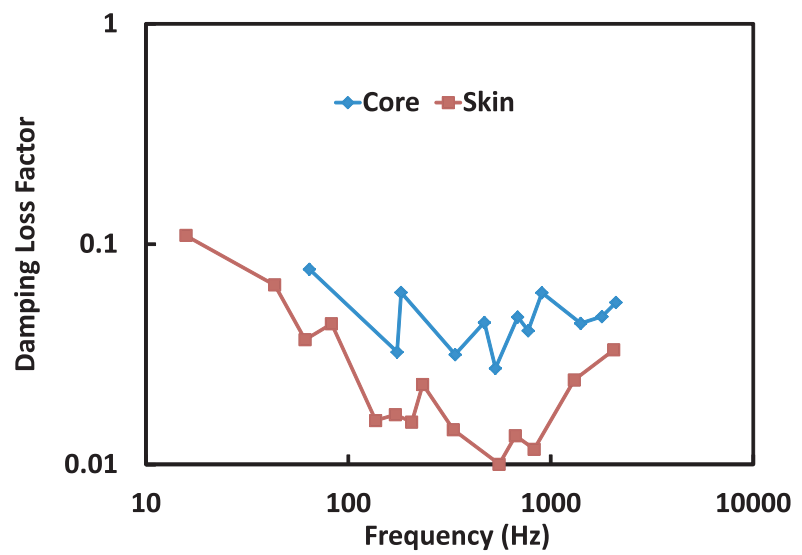

Figure 7. The damping loss factors of the core and the skins of a $23 \mathrm{~mm}$ thick sandwich panel measured using beams with both ends free.

\subsection{Mass-stiffness-mass resonant frequency}

The mass-stiffness-mass resonant frequency $f_{m s m}$ of a triple laminate panel can be calculated using equation (1) of Ballagh ${ }^{21}$ which is given in the following equation (19).

$$
f_{m s m}=\frac{1}{2 \pi} \sqrt{\frac{E_{2}\left(m_{1}+m_{3}\right)}{b m_{1} m_{3}}}
$$

In this equation, $m_{1}$ and $m_{3}$ are the masses per unit area of the two skins, $E_{2}$ is the Young's modulus of the core and $b$ is the thickness of the core. Note that the missing divide by $2 \pi$ has been inserted into Ballagh's incorrect version of this equation.

The measured mass per unit area of the delaminated skins $\left(2.43\right.$ and $\left.2.1 \mathrm{~kg} / \mathrm{m}^{2}\right)$ and the measured Young's modulus of the delaminated core of the $23 \mathrm{~mm}$ thick panel were used to calculate the mass-stiffness-mass resonant frequency of the $23 \mathrm{~mm}$ panel. The calculated resonant frequency was $10.7 \mathrm{kHz}$. For the 14 and $42 \mathrm{~mm}$ panels, the only relevant information was the manufacturer's stated skin mass per unit area of 0.41 and $0.265 \mathrm{~kg} / \mathrm{m}^{2}$ respectively. Thus, although all cores had different densities, the Young's moduli of the cores of the 14 and $42 \mathrm{~mm}$ panels were assumed to be the same as that of the 23 panel. Making this assumption, gave the mass-stiffness-mass resonant frequencies as 31.6 and $21.5 \mathrm{kHz}$ for the 14 and $42 \mathrm{~mm}$ panels respectively.

\section{SOUND INSULATION}

The sound insulation of the three sandwich panels was measured using the sound intensity technique ${ }^{1}$. A diffuse sound field was produced in a $216 \mathrm{~m}^{3}$ reverberation room. The sound pressure level was measured at 5 microphone positions in the reverberation room. A sample of the sandwich panel measuring 1.546 by $0.946 \mathrm{~m}$ was mounted in one wall of the reverberation room. The room on the other side of the 
sample was converted to a semi-anechoic room by lining it with sound absorbing material and three separate intensity scans of the surface of the sample in the semianechoic room were conducted.

Davy's ${ }^{3}$ theory was used to make the predictions. It was modified to allow the Young's modulus to vary with frequency. The Young's modulus and critical frequency were calculated for each prediction frequency using the experimentally derived regression equations or theoretical calculations. The thick panel shearing correction was not used since this effect is being accounted for by the frequency variable Young's modulus.

Figure 8 compares the measured sound reduction index of the $23 \mathrm{~mm}$ thick sandwich panel with theoretical predictions using three different estimations of the Young's modulus as a function of frequency. Ecalc was calculated using the theory of Kurtze and Watters ${ }^{8}$ and the measured Young's moduli of the skin and core. Efixed and Efree were calculated using Young's moduli calculated from equations (15) and (16) which were derived from the measurements on the fixed-free and free-free beams respectively. The measured values of Young's moduli produced better agreement with experiment than the calculated ones. The free-free values produced better agreement than the fixed-free values. However, overall the agreement between theory and experiment was disappointing. The decrease in the measured sound insulation from 8 to $10 \mathrm{kHz}$ is probably due to the fact that the calculated mass-stiffness-mass resonant frequency is $10.7 \mathrm{kHz}$.

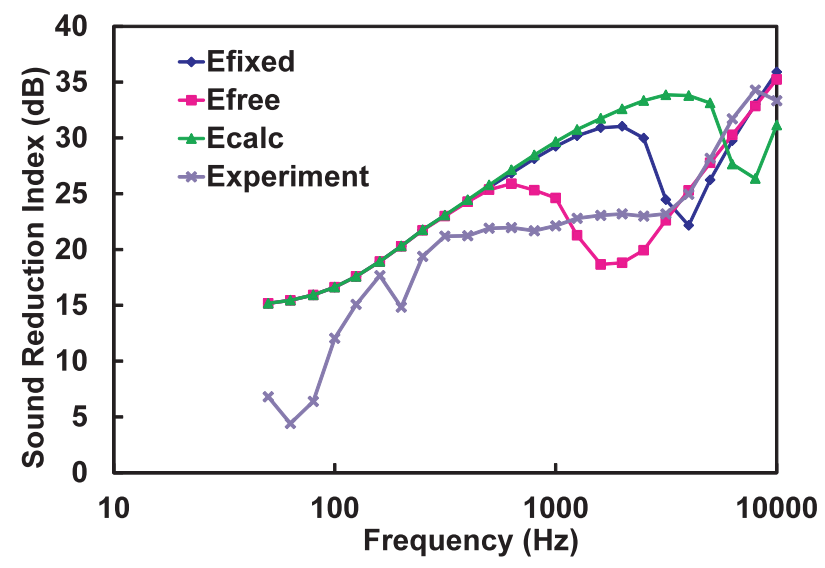

Figure 8. The comparison of the measured and predicted sound insulation of a 23 mm thick sandwich panel. The Efixed prediction was made using the effective Young's modulus and the effective damping loss factor measured using a beam with one clamped (fixed) end and one free end. The Efree prediction was made using the effective Young's modulus and the effective damping loss factor measured using a beam with both ends free. The Ecalc prediction was made using the effective Young's modulus calculated from the measured Young's moduli of the skins and core of the laminate using the theory of Kurtze and Watters ${ }^{8}$. The Ecalc prediction used the effective damping loss factor measured using a beam with one clamped (fixed) end and one free end. 
The comparison of the theoretical and the experimental sound insulation for the 14 $\mathrm{mm}$ sandwich panel is shown in Figure 9. The Exp1 values were measured by the second author of this paper and the Exp2 values were measured by Anders ${ }^{7}$. There is reasonable agreement between the Exp1 values and the theoretical values below $2 \mathrm{kHz}$ and between the theoretical values and the Exp2 values from 80 to $1250 \mathrm{~Hz}$. Above 2 $\mathrm{kHz}$, the agreement between theory and experiment is disappointing. Figure 10 shows the poor agreement between the theoretical and the experimental values for the $42 \mathrm{~mm}$ sandwich panel. Exp1 and Exp2 have the same meaning as in Figure 9.

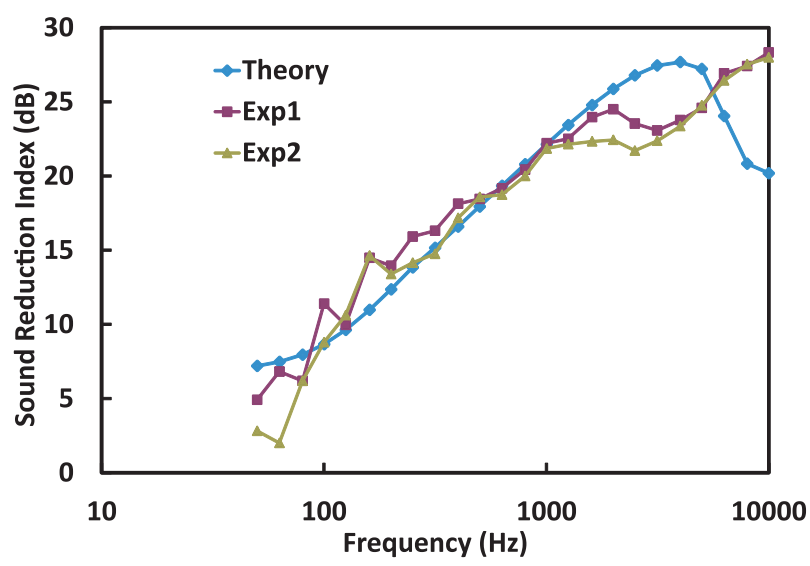

Figure 9. The comparison between the predicted and two experimental measurements of the sound insulation of a $14 \mathrm{~mm}$ thick sandwich panel. The theoretical prediction was made using the effective Young's modulus and the effective damping loss factor measured using a beam with one clamped (fixed) end and one free end.

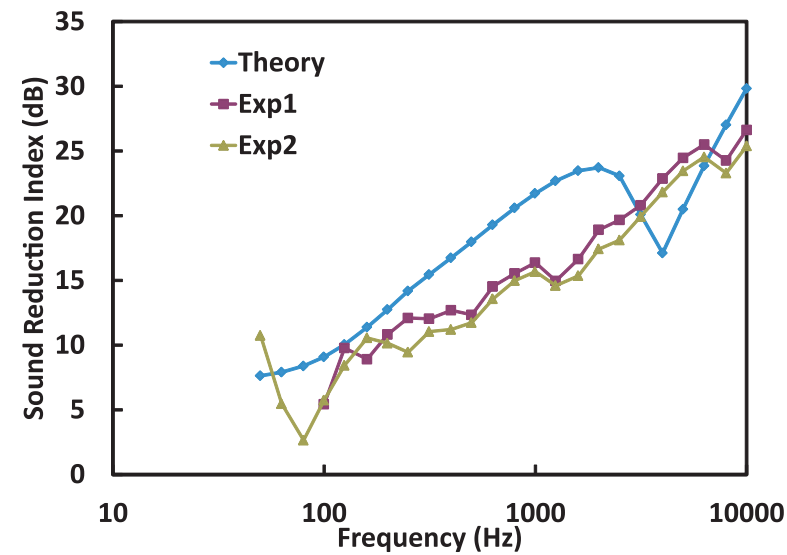

Figure 10. The comparison between the predicted and two experimental measurements of the sound insulation of a $42 \mathrm{~mm}$ thick sandwich panel. The theoretical prediction was made using the effective Young's modulus and the effective damping loss factor measured using a beam with one clamped (fixed) end and one free end. 
Because of the reasonable agreement between the different methods of determining the effective Young's moduli of the beams, it was a surprise to discover that the agreement between the theoretical predictions and the experimental measurements of the sound insulation was not greatly improved unless the back calculated values of the Young's moduli were used. This is believed to be due to the fact that many of the prediction frequencies fall in the critical frequency dip because of the variation of the Young's moduli with frequency. Unfortunately the theoretical prediction techniques are not very accurate in the region of the critical frequency dip and are very sensitive to the value of the Young's modulus and the damping loss factor. This observation agrees with that of Brunskog", who stated that "The agreement with experimental results is reasonable, but not perfect. The most problematic frequency range is around the critical frequency, where the dip in the transmission loss is too sharp." The theory also over predicts the sound insulation of the 23 and $46 \mathrm{~mm}$ thick sandwich panels at most of the lower frequencies.

Nilsson ${ }^{14}$ used a similar model of sound insulation to that used in in this paper. $\mathrm{He}$ obtained better agreement between theory and experiment using calculated values of Young's modulus than was observed in this paper. However it should be noted than the skins of Nilsson's sandwich panel were thicker and heavier than the skins of the sandwich panels studied in this paper. Nilsson's skins had a thickness of $5 \mathrm{~mm}$ and a surface density of $8.8 \mathrm{~kg} / \mathrm{m}^{2}$. The thicknesses of the skins of the sandwich panels studied in this paper were about $2 \mathrm{~mm}$ and their surface densities ranged from 0.265 to $2.43 \mathrm{~kg} / \mathrm{m}^{2}$.

\section{CONCLUSION}

The effective Young's modulus of a three layered sandwich panel with a core whose Young's modulus is much less the Young's modulus of its skins can vary with frequency because of the shearing of the core as predicted by the theory of Kurtze and Watters ${ }^{8}$. Unfortunately, the use of a predicted or measured Young's modulus which varies with frequency does not improve the agreement between the predicted sound insulation and the measured sound insulation of the sandwich panel as much as had been hoped. This is because many of the prediction frequencies lie in the critical frequency dip because of the variation of the Young's modulus with frequency. Small changes in the Young's modulus and changes in the damping loss factor can have a large effect on the predicted sound insulation. Nevertheless, the use of a variable Young's modulus does improve the prediction of the sound insulation of a sandwich panel.

The best agreement between the predicted sound insulation and the measured sound insulation was obtained when the Young's modulus was measured with a free-free beam. The agreement was worse when the Young's modulus was measured with a fixed-free beam, and worse again when it was calculated from the measured Young's moduli of the skins and core using the theory of Kurtze and Watters ${ }^{8}$. For two of the sandwich panels, the sound insulation theory over predicted the measured sound insulation at low frequencies. 


\section{REFERENCES}

1. ISO, ISO 15186-2:2003 Acoustics - Measurement of sound insulation in buildings and of building elements using sound intensity - Part 2: Field measurements. International Organization for Standardization: Geneva, Switzerland, 2003; pp 1-25.

2. ASTM, ASTM E 756 - 05 Standard Test Method for Measuring VibrationDamping Properties of Materials (Reapproved 2010). ASTM International: West Conshohocken, USA, 2010; pp 1-14.

3. Davy, J.L., Predicting the sound insulation of single leaf walls: Extension of Cremer's model. Journal of the Acoustical Society of America 2009, 126(4), 1871-1877.

4. Brunskog, J., The forced sound transmission of finite single leaf walls using a variational technique. Journal of the Acoustical Society of America 2012, 132(3), 1482-1493.

5. Nilsson, E., Nilsson, A.C., Prediction and measurement of some dynamic properties of sandwich structures with honeycomb and foam cores. Journal of Sound and Vibration 2002, 251(3), 409-430.

6. Cremer, L., Heckl, M., Petersson, B.A.T., Structure-borne sound - Structural vibrations and sound radiation at audio frequencies, Third edition. SpringerVerlag: Berlin, Germany, 2005; pp 1-607.

7. Anders, S. Sound Transmission Loss of Sandwich Panels. Master of Engineering Thesis University of Canterbury, Christchurch, New Zealand, 2010.

8. Kurtze, G., Watters, B.G., New wall design for high transmission loss or high damping. Journal of the Acoustical Society of America 1959, 31(6), 739-748.

9. Ford, R.D., Lord, P., Walker, A.W., Sound transmission through sandwich constructions. Journal of Sound and Vibration 1967, 5(1), 9-21.

10. Dym, C.L., Lang, M.A., Transmission of sound through sandwich panels. Journal of the Acoustical Society of America 1974, 56(5), 1523-1532.

11. Dym, C.L., Ventres, C.S., Lang, M.A., Transmission of sound through sandwich panels - reconsideration. Journal of the Acoustical Society of America 1976, 59(2), 364-367.

12. Jones, R.E., Field sound insulation of load-bearing sandwich panels for housing. Noise Control Engineering Journal 1981, 16(2), 90-105.

13. Makris, S.E., Dym, C.L., Smith, J.M., Transmission loss optimization in acoustic sandwich panels. Journal of the Acoustical Society of America 1986, 79(6), 18331843.

14. Nilsson, A.C., Wave-propagation in and sound-transmission through sandwich plates. Journal of Sound and Vibration 1990, 138(1), 73-94.

15. Moore, J.A., Lyon, R.H., Sound-transmission loss characteristics of sandwich panel constructions. Journal of the Acoustical Society of America 1991, 89(2), 777-791. 
16. Lauriks, W., Mees, P., Allard, J.F., The acoustic transmission through layered systems. Journal of Sound and Vibration 1992, 155(1), 125-132.

17. Bolton, J.S., Shiau, N.M., Kang, Y.J., Sound transmission through multi-panel structures lined with elastic porous materials. Journal of Sound and Vibration 1996, 191(3), 317-347.

18. Wang, T., Li, S., Rajaram, S., Nutt, S.R., Predicting the Sound Transmission Loss of Sandwich Panels by Statistical Energy Analysis Approach. Journal of Vibration and Acoustics-Transactions of the Asme 2010, 132(1), 1-7.

19. Sargianis, J., Suhr, J., Vibration and wave number characterization in carbon-fiber sandwich composite structures. In Goulbourne, N.C., Ounaies, Z., eds.Behavior and Mechanics of Multifunctional Materials and Composites 2012, 2012; Vol. 8342, pp 1-9.

20. Rindel, J.H., Dispersion and absorption of structure-borne sound in acoustically thick plates. Applied Acoustics 1994, 41(2), 97-111.

21. Ballagh, K.O., Adapting simple prediction methods to sound transmission of lightweight foam cored panels. New Zealand Acoustics 2011, 24(4), 28-30, 32. 